\title{
Diagnostic performance of T1- and T2-mapping in HTx patients to identify acute cellular rejection (ACR) in comparison to conventional CMR techniques and endomyocardial biopsy (EMB) as the standard of reference
}

\author{
Lysann Reinhardt*, Matthias Gutberlet \\ From 18th Annual SCMR Scientific Sessions \\ Nice, France. 4-7 February 2015
}

\section{Background}

Cardiovascular magnetic resonance (CMR) is an excellent non invasive method for lifelong post HTX staging, feasible to identify patients with an acute cellular rejection (ACR). This study evaluates the diagnostic performance of T1- and T2-Mapping CMR to identify biopsy proven acute cellular rejection (ACR) in comparison to conventional CMR techniques.

\section{Methods}

Thirty-five CMRs were performed (mean age $53 \pm 11$ years, $24 \mathrm{male}$ ) using a $1.5 \mathrm{~T}$ scanner (Achieva, Philips medical systems, Best, The Netherlands) compared to EMB. The CMR-protocol included conventional sequences to assess myocardial edema ratio (ER), a T1-weighted spinecho sequence for global relative enhancement (gRE) and inversion recovery sequences to visualize late gadolinium enhancement (LE). Histological grading according to the International Society for Heart and Lung Transplantation (ISHLT) from 1990, in which grade $\geq 1 \mathrm{~B}$ was considered as a clinically relevant ACR, which has to be treated.

T1-quantification was performed using the modified Look-Locker inversion-recovery (MOLLI) sequence before and 15 minutes after administration of $0.1 \mathrm{mmol} / \mathrm{kg}$ body weight of Gadobutrol (Gadovist, Bayer HealthCare, Berlin, Germany). T2-quantification was performed using a freebreathing, navigator-gated multi-echo-sequence. Global

\footnotetext{
Department of Diagnostic and Interventional Radiology, University Leipzig -
} Heart Center Leipzig, Leipzig, Germany

(C) 2015 Reinhardt and Gutberlet; licensee BioMed Central Ltd. This is an Open Access article distributed under the terms of the Creative Commons Attribution License (http://creativecommons.org/licenses/by/4.0), which permits unrestricted use, distribution, and reproduction in any medium, provided the original work is properly cited. The Creative Commons Public Domain Dedication waiver (http://creativecommons.org/publicdomain/zero/1.0/) applies to the data made available in this article, unless otherwise stated.

myocardial T1 pre- and post-contrast, T2 and ECV maps were calculated with a dedicated Software (cvi42).

\section{Results}

In 20/35 (57\%) EMBs there was no or mild ACR (ISHLT 0A, 1A) and a clinically relevant ACR in 15/35 EMBs (1B, 2A, 4A).

The best Receiver Operating Characteristics (ROC) with high values for the area-under-the-curve (AUC) - to discriminate between relevant and non-relevant ACR - were demonstrated by postcontrast myocardial T1-mapping (0.78), myocardial T2-mapping (0.73) and native myocardial T1-mapping (0.65), respectively. Comparable results were achieved with the calculated value of the extracellular volume (ECV) with 0.66 . The conventional CMR techniques ER and gRE revealed only moderate results with 0.54 and 0.52 , respectively. Similar to myocarditis the critical values for ER were $\geq 2$ and $\geq 4.5$ for the gRE.

Accordingly, the best sensitivity and specificity for clinically relevant $A C R \geq 1 B$ could be achieved with postcontrast T1-mapping using a cut off-value of $342 \mathrm{~ms}$ $(73 \% / 70 \%)$ and $\mathrm{T} 2$-mapping using a cut off value of $65 \mathrm{~ms}(73 \% / 75 \%)$, respectively. Again comparable results could be achieved with the ECV using a cut off of $42(67 \% / 70 \%)$ and moderate results by using native T1mapping with a cut off of $1060 \mathrm{~ms}(87 \% / 45 \%)$.

\section{Conclusions}

Parametric CMR is encouraging to identify subclinical ACR in patients after HTx, especially postcontrast T1and T2-mapping. However, larger studies are needed to 
underline this and potentially reduce, or eliminate the need for EMB.

\section{Funding}

In-house research funds.

Published: 3 February 2015

doi:10.1186/1532-429X-17-S1-Q54

Cite this article as: Reinhardt and Gutberlet: Diagnostic performance of T1- and T2-mapping in HTx patients to identify acute cellular rejection (ACR) in comparison to conventional CMR techniques and

endomyocardial biopsy (EMB) as the standard of reference. Journal of

Cardiovascular Magnetic Resonance 2015 17(Suppl 1):Q54.

Submit your next manuscript to BioMed Central and take full advantage of:

- Convenient online submission

- Thorough peer review

- No space constraints or color figure charges

- Immediate publication on acceptance

- Inclusion in PubMed, CAS, Scopus and Google Scholar

- Research which is freely available for redistribution

Submit your manuscript at www.biomedcentral.com/submit
C Biomed Central 